\title{
The role of thyroid hormone nuclear receptors in the heart: evidence from pharmacological approaches
}

\author{
Wilmar M. Wiersinga
}

Published online: 19 December 2008

(c) The Author(s) 2008. This article is published with open access at Springerlink.com

\begin{abstract}
This review evaluates the hypothesis that the cardiac effects of amiodarone can be explained-at least partly_by the induction of a local 'hypothyroid-like condition' in the heart. Evidence supporting the hypothesis comprises the observation that amiodarone exerts an inhibitory effect on the binding of T3 to thyroid hormone receptors (TR) alpha-1 and beta-1 in vitro, and on the expression of particular T3-dependent genes in vivo. In the heart, amiodarone decreases heart rate and alpha myosin heavy chain expression (mediated via TR alpha-1), and increases sarcoplasmic reticulum calcium-activated ATPase and beta myosin heavy chain expression (mediated via TR beta-1). Recent data show a significant similarity in expression profiles of 8,435 genes in the heart of hypothyroid and amiodarone-treated animals, although similarities do not always exist in transcripts of ion channel genes. Induction of a hypothyroid cardiac phenotype by amiodarone may be advantageous by decreasing energy demands and increasing energy availability.
\end{abstract}

Keywords Amiodarone - Dronedarone ·

Hypothyroidism - Thyroid hormone receptor alpha-1 . Thyroid hormone receptor beta-1 - Heart rate .

Alpha MHC $\cdot$ Beta MHC $\cdot$ SERCA2a

\section{Introduction}

The heart is an important target organ for thyroid hormone as evident from clinical practice [1]. In hyperthyroid

W. M. Wiersinga $(\bowtie)$

Department of Endocrinology and Metabolism, Academic

Medical Center, University of Amsterdam,

Amsterdam, The Netherlands

e-mail: w.m.wiersinga@amc.uva.nl patients there is an increased resting heart rate, increased left ventricular contractility, increased cardiac output and a decreased systemic vascular resistance, resulting in a lower diastolic and higher systolic blood pressure; serum cholesterol is decreased and patients are susceptible to cardiac arrhythmias, specifically to atrial fibrilation. In contrast, hypothyroid patients have a decreased heart rate, impaired cardiac contractility and diastolic function, decreased cardiac output and an increased systemic vascular resistance, resulting in a higher diastolic blood pressure; serum cholesterol is increased and patients are susceptible to accelerated atherosclerosis and coronary artery disease. The aberrant cardiovascular functions in hyperthyroid and hypothyroid patients are usually fully reversible upon restoration of the euthyroid state.

Amiodarone, introduced originally as an anti-anginal agent but nowadays used as a very potent antiarrhytmic drug, lowers heart rate, lengthens the cardiac action potential (manifest as a longer QTc interval on the EKG), and depresses myocardial oxygen consumption [2]. In addition, amiodarone increases plasma cholesterol [3]. Similarities between the effects of amiodarone and of hypothyroidism are striking. It has therefore been hypothesized that the cardiac effects of amiodarone can be explained-at least partly - by the induction of a local 'hypothyroid-like' condition in the heart [3]. In this review we present evidence in favour of this hypothesis derived from experimental animal studies focussing on nuclear T3 receptors and thyroid hormone-dependent gene expression in the heart.

\section{Hypothyroidism}

Genomic effects of thyroid hormone in the heart are mediated via nuclear $\mathrm{T} 3$ receptors (TR). There are several 
isoforms of TRs: TR $\alpha 1$ and TR $\beta 1$ (which both bind the ligand T3) and TR $\alpha 2$ (which does not bind $\mathrm{T} 3$ but is able to bind to thyroid response elements (TRE) and may exert a dominant negative effect on gene expression). The heart is a predominantly TR $\alpha 1$ organ, although TR $\beta 1$ is also expressed albeit at a lower level. In rats made hypothyroid by adding $0.05 \%$ propylthiouracil to their drinking water for 2 weeks, we did not observe any changes in atrial or ventricular gene expression of the three TRs relative to controls, neither at the mRNA level nor at the protein level [4]. Other models, however, did show changes in the expression of particular TR isoforms in hypothyroid rats [5, 6]. The discrepancy can be explained by the more severe hypothyroidism in these earlier studies by using propylthiouracil for a longer period of time (six instead of our 2 weeks) or combining propylthiouracil with a low iodine diet [5, 6]. Because in our model cardiac TR levels are not affected by thyroid hormone deficiency, observed changes in the expression of T3-dependent genes in the hypothyroid heart are likely attributed to a low occupancy rate of TR with T3.

There are a number of T3-responsive genes in the heart encoding for proteins involved in cardiac contractility. Examples are the sarcoplasmic reticulum calcium-activated ATPase (SERCA2a) which is responsible for the calcium reuptake during the diastole and is activated by T3 [7], and the two myosin heavy chains $\alpha$ and $\beta$ ( $\alpha \mathrm{MHC}$ and $\beta \mathrm{MHC}$, respectively) which are myofibrillar proteins that make up the thick filament of the cardiac myocyte contractile apparatus. In rodents, transcription of $\alpha \mathrm{MHC}$ is activated by $\mathrm{T} 3$, whereas transcription of $\beta \mathrm{MHC}$ is repressed by $\mathrm{T} 3$ $[8,9]$. In our experimental model, hypothyroidism was associated with a downregulation of $\alpha \mathrm{MHC}$ and an upregulation of $\beta \mathrm{MHC}$ (both at the mRNA and at the protein level) in atria and ventricles; SERCA2a was significantly downregulated in atria and ventricles [4]. The observed changes are in good agreement with previous reports in the literature [8-10]. Downregulation of $\alpha \mathrm{MHC}$ (the fast myosin with higher ATPase activity) under simultaneous upregulation of $\beta \mathrm{MHC}$ (the slow myosin), together with the downregulation of SERCA2a explains to a certain extent the decreased cardiac contractility associated with hypothyroidism [1]. Modulation of $\alpha \mathrm{MHC}$ transcription is linked to the TR $\alpha 1$ isoform, whereas transcription of $\beta \mathrm{MHC}$ and SERCA2a genes seems to be under control of TR $\beta 1$ [11].

\section{Amiodarone}

Amiodarone treatment (100 mg/kg/day orally for 2 weeks) influences cardiac TR mRNA expression [12]: TR $\alpha 1$ is decreased in the right atrium but increased in the left ventricular wall, $\mathrm{TR} \alpha 2$ remains unchanged at these locations, and TR $\beta 1$ is decreased both in the right atrium and the left ventricular wall. The overall downregulation of TR by amiodarone is similar to the reported downregulation of $\operatorname{TR} \alpha 1$ and $\operatorname{TR} \beta 1$ in the post-infarcted rat heart, which shows a hypothyroid cardiac phenotype [13].

Amiodarone treatment also influenced thyroid hormonedependent gene expression in our experimental rat model at the mRNA level [12]: SERCA2a was reduced in the right atrium, $\alpha \mathrm{MHC}$ was reduced both in the right atrium and left ventricular apex, whereas $\beta \mathrm{MHC}$ was increased in the right atrium, left ventricular wall and apex. The findings are in good agreement with the literature [14].

The data strongly suggests that amiodarone induces a hypothyroid-like phenotype with regard to T3-dependent gene expression in the heart. To learn about the mechanism by which amiodarone exerts these effects, we performed a number of in vitro and in vivo studies. First, in vitro experiments demonstrated that amiodarone via its main metabolite desethylamiodarone (DEA) acts as a competitive inhibitor of T3 binding to TR $\alpha 1$ (IC50 value $30 \pm 3.9 \mu \mathrm{M}$ ) and as a noncompetitive inhibitor of T3 binding to TR $\beta 1$ (IC50 value $71 \pm 3.4 \mu \mathrm{M}$ ) $[15,16]$. Next to inhibition of T3 binding to TR, DEA may further affect T3-dependent gene expression by inhibition of co-activator binding to TR and inhibition of the TR binding to TRE [17, 18]. Second, DEA concentrations in the rat heart after amiodarone treatment $(100 \mathrm{mg} / \mathrm{kg} / \mathrm{day}$ orally for 2 weeks) are in the micromolar range $(14 \mu \mathrm{mol} / \mathrm{kg})$ [19], close to the IC50 values of DEA for inhibiting T3 binding to TR in vitro. The T3 concentrations in rat heart are 4 times lower in amiodarone-treated animals than in control animals ( $1 \mathrm{vs} 4 \mathrm{nmol} / \mathrm{kg}$, respectively) [20]. The marked decrease in myocardial T3 concentration is related to the decrease of plasma $\mathrm{T} 3$ and the impaired entrance of plasma-derived $\mathrm{T} 3$ in hearts of amiodarone-treated animals [21]. The reduction of cardiac TR and $\mathrm{T} 3$ concentrations will result in all likelihood in a low occupancy of TR with T3, which favours the inhibitory effects of DEA [15, 16]. The finding that amiodarone modulates the gene expression of both $\alpha \mathrm{MHC}$ (mediated via $\mathrm{TR} \alpha 1)$ and $\beta \mathrm{MHC}$ and SERCA2a (mediated via TR $\beta 1$ ) is in line with the inhibitory effect of DEA on the binding of T3 to both $\operatorname{TR} \alpha 1$ and $\operatorname{TR} \beta 1$.

\section{Dronedarone}

Dronedarone is a newly developed antiarrhythmic drug, structurally related to amiodarone. It lacks, however, the iodine moiety of amiodarone, and thereby iodine-related toxicity. Dronedarone like amiodarone has antiadrenergic effects as well as blocking effects on many ion channels. Dronedarone possesses rate-control and rhythm-control properties, and seems to be safe and effective in preventing 
recurrence of atrial fibrillation [22]. We wondered if part of the pharmacological actions of dronedarone could also be attributed to induction of a local hypothyroid-like condition in the heart.

In vitro experiments demonstrate that debutyldronedarone (the major metabolite of dronedarone) inhibits the binding of T3 to TR $\alpha 1$ (IC50 value $59 \pm 4.1 \mu \mathrm{M}$ ) much more strongly than the binding of T3 to TR $\beta 1$ (IC50 value $280 \pm 29 \mu \mathrm{M})$ [23]. Inhibition of T3 binding to TR $\alpha 1$ by debutyldronedarone is competitive in nature. Treating rats with dronedarone $(100 \mathrm{mg} / \mathrm{kg} /$ day orally for 2 weeks $)$ decreases TR $\alpha 1$ mRNA in the right atrium, decreases TR $\beta 1$ mRNA in right atrium, left ventricular wall and apex, whereas it does not affect TR $\alpha 2$ mRNA in the heart [12]. With regard to T3-dependent gene expression, dronedarone did not change $\alpha \mathrm{MHC}, \beta \mathrm{MHC}$ and SERCA2a expression in the heart [12]. Pantos et al. [24] also did not observe a change in $\beta \mathrm{MHC}$ or SERCA2a cardiac expression in rats treated with dronedarone $(90 \mathrm{mg} / \mathrm{kg} / \mathrm{d}$ orally for 2 weeks), but did find a significant decrease in $\alpha \mathrm{MHC}$ and heart rate. These findings are most interesting: the presence of an effect of dronedarone on heart rate and $\alpha \mathrm{MHC}$ (both TR $\alpha 1$ mediated) and the absence of an effect of dronedarone on $\beta$ MHC and SERCA2a (both TR $\beta 1$ mediated) reinforce the in vitro findings that dronedarone acts as a selective TR $\alpha 1$ antagonist. This has also been demonstrated in another rat study in which treatment with amiodarone reduced the expression of two TR $\beta 1$-dependent genes (as evident from a lower LDL receptor protein concentration and a lower iodothyronine- $5^{\prime}$-deiodinase-activity in liver), whereas treatment with dronedarone did not [23].

Whether dronedarone like amiodarone also induces a local hypothyroid-like condition in the heart is less clear. However, further biochemical and functional studies showed many similarities in hearts of hypothyroid and dronedarone-treated rats, leading these authors to conclude that dronedarone treatment results in cardioprotection by selectively mimicking hypothyroidism [24].

\section{Hypothyroid cardiac phenotype}

Amiodarone treatment, like hypothyroidism, lowers heart rate, lenghthens the QTc interval, and lowers $\alpha$ MHC gene expression in the heart; these effects are TR $\alpha 1$-mediated effects. Amiodarone treatment, like hypothyroidism, increases $\beta \mathrm{MHC}$ and decreases SERCA2a gene expression in the heart; both effects are TR $\beta 1$-mediated effects. The data provides supportive evidence for the hypothesis that amiodarone induces a hypothyroid-like condition in the heart. Amiodarone apparently switches gene expression back into foetal programming of particular cardiac genes, which might have survival value for the organism.
The hypothesis is further strengthened by recent data from a microarray analysis of 8,435 genes in the left ventricular myocardium of rats [25]. There was a very significant similarity in expression profiles between hypothyroid and amiodarone-treated rats $(R=0.63, P<0.00001)$; the correlation became even stronger when the top 100 up-regulated and 100 down-regulated genes in hypothyroidism were analyzed $(R=0.78, P<0.00001)$.

As a final remark, however, it should be mentioned that not all pharmacological actions of amiodarone can be explained from the induction of a local hypothyroid-like condition in the heart. Evaluating the complete ion channel repertoire by real time PCR in hearts of mice treated with amiodarone, it became obvious that changes in transcript levels sometimes were similar to those seen in hypothyroid mice, but very frequently were completely different from the hypothyroid phenotype [26, 27]. Nevertheless, downregulation of the effect of thyroid hormone in the heart results in what has been called "cardiac metamorphosis" [28], which by decreasing energy demands and increasing energy availability might be advantageous with potential therapeutic implications.

Open Access This article is distributed under the terms of the Creative Commons Attribution Noncommercial License which permits any noncommercial use, distribution, and reproduction in any medium, provided the original author(s) and source are credited.

\section{References}

1. Klein I, Danzi S (2007) Thyroid disease and the heart. Circulation 116:1725-1735. doi:10.1161/CIRCULATIONAHA.106.678326

2. Singh BN, Vaughan Williams EM (1970) The effect of amiodarone, a new anti-anginal drug on cardiac muscle. $\mathrm{Br} \mathrm{J}$ Pharmacol 39:657-667

3. Wiersinga WM, Trip MD, Van Beeren MH, Plomp TA, Oosting $H$ (1991) An increase in plasma cholesterol independent of thyroid function during long-term amiodarone therapy. A dosedependent relationship. Ann Intern Med 114:128-132

4. Stoykov I (2006) Thyroid hormone receptors in the heart. Thesis, University of Amsterdam, The Netherlands

5. Sadow PM, Chassande O, Koo EK et al (2003) Regulation of expression of thyroid hormone receptor isoforms and coactivators in liver and heart by thyroid hormone. Mol Cell Endocrinol 203:65-75. doi:10.1016/S0303-7207(03)00122-9

6. Hodin RA, Lazar MA, Chin WW (1990) Differential and tissuespecific regulation of the multiple rat c-erbA messenger RNA species by thyroid hormone. J Clin Invest 85:101-105. doi:10.1172/JCI114398

7. Hartong R, Wang N, Kurokawa R et al (1994) Delineation of three different thyroid response elements in promoter of rat sarcoplasmic reticulum $\mathrm{Ca}++$ ATPase gene: demonstration that retinoid $\mathrm{X}$ receptor binds $5^{\prime}$ to thyroid hormone receptor in response element 1. J Biol Chem 269:13021-13029

8. Franklyn JA, Green NK, Gammage MD et al (1989) Regulation of $\alpha$ - and $\beta$-myosin heavy chain messenger RNAs in the myocardium by amiodarone and thyroid status. Clin Sci 76:463-467

9. Morkin E (1993) Regulation of myosin heavy chains in the heart. Circulation 87:1451-1460 
10. Danzi S, Ojamaa K, Klein I (2003) Triiodothyronine-mediated myosin heavy chain gene transcription in the heart. Am J Physiol Heart Circ Physiol 284:H 2255-H 2262

11. Kinugawa K, Yonekura K, Ribeiro RCJ et al (2001) Regulation of thyroid hormone receptor isoforms in physiological and pathological cardiac hypertrophy. Circ Res 89:591-598. doi:10.1161/ hh1901.096706

12. Stoykov I, Van Beeren HC, Moorman AFM, Christoffels VM, Wiersinga WM, Bakker O (2007) Effect of amiodarone and dronedarone administration on thyroid hormone-dependent gene expression in different cardiac components. Eur J Endocrinol 156:695-702. doi:10.1530/EJE-07-0017

13. Pantos C, Mourouzis I, Saranters T et al (2005) Thyroid hormone receptors alpha 1 and beta 1 are downregulated in the postinfarcted rat heart: consequences on the response to ischaemicreperfusion. Basic Res Cardiol 100:422-432. doi:10.1007/ s00395-005-0545-4

14. Kahaly GJ, Dillman WH (2005) Thyroid hormone action in the heart. Endocr Rev 26:704-728. doi:10.1210/er.2003-0033

15. Van Beeren HC, Bakker O, Wiersinga WM (1995) Desethylamiodarone is a competetive inhibitor of the binding of thyroid hormone to the thyroid hormone $\alpha 1$-receptor protein. Mol Cell Endocrinol 112:15-19. doi:10.1016/0303-7207(95)03578-U

16. Bakker O, Van Beeren HC, Wiersinga WM (1994) Desethylamiodarone is a noncompetetive inhibitor of the binding of thyroid hormone to the thyroid hormone $\beta 1$-receptor protein. Endocrinology 134:1665-1670. doi:10.1210/en.134.4.1665

17. Van Beeren HC, Bakker O, Wiersinga WM (2000) Desethylamiodarone interferes with the binding of co-activator GRIP to the beta 1 thyroid hormone receptor. FEBS Lett 481:213-216. doi:10.1016/S0014-5793(00)01970-0

18. Bogazzi F, Bartalena L, Brogioni S et al (2001) Desethylamiodarone antagonizes the effect of thyroid hormone at the molecular level. Eur J Endocrinol 145:59-64. doi:10.1530/eje.0. 1450059

19. Plomp TA, Wiersinga WM, Maes RA (1985) Tissue distribution of amiodarone and desethylamiodarone in rats after repeated oral administration of various amiodarone dosages. Arzneimittelforschung 35:1805-1810

20. Schröder-van der Elst JP, Van der Heide D (1990) Thyroxine, T3, and reverse $\mathrm{T} 3$ concentrations in several tissues of the rat: effects of amiodarone and desethylamiodarone on thyroid hormone metabolism. Endocrinology 127:1656-1664

21. Gotzsche LB, Orskov H (1994) Cardiac triiodothyronine nuclear receptor binding capacities in amiodarone-treated, hypo- and hyperthyroid rats. Eur J Endocrinol 130:281-290

22. Singh BN, Connolly SJ, Cryns HJ et al (2007) Dronedarone for maintenance of sinus rhythm in atrial fibrillation or flutter. N Engl J Med 357:987-999. doi:10.1056/NEJMoa054686

23. Van Beeren HC, Jong WM, Kaptein E et al (2003) Dronedarone acts as a selective inhibitor of $3,5,3^{\prime}$-triiodothyronine binding to thyroid hormone receptor-alpha 1: in vitro and in vivo evidence. Endocrinology 144:552-558. doi:10.1210/en.2002-220604

24. Pantos C, Mourouzis I, Malliopoulou V et al (2005) Dronedarone administration prevents body weight gain and increases tolerance of the heart to ischemic stress: a possible involvement of thyroid hormone receptor $\alpha 1$. Thyroid 15:16-23. doi:10.1089/thy.2005. 15.16

25. Shi R-q, Lee J-K, Hayashi Y et al (2007) Long term amiodarone treatment causes cardioselective hypothyroid-like alteration in gene expression profile. Eur J Pharmacol 578:270-278. doi: 10.1016/j.ejphar.2007.09.039

26. Le Bouter S, Demolombe S, Chambellan A et al (2003) Microarray analysis altered thyroid status: relation to cellular and integrated electrophysiology. Circ Res 92:234-242. doi:10.1161/01. RES.0000053185.75505.8E

27. Le Bouter S, El Harchi A, Marionneau C et al (2004) Long-term amiodarone administration remodels expression of ion channels transcripts in the mouse heart. Circulation 110:3028-3035. doi: 10.1161/01.CIR.0000147187.78162.AC

28. Pantos C, Mourouzis I, Xinaris C et al (2008) Thyroid hormone and "cardiac metamorphosis": potential therapeutic implications. Pharmacol Ther 118:277-294. doi:10.1016/j.pharmthera.2008. 02.011 